\title{
Telecommuting to Improve Quality-of-Worklife of Women Workers in Lagos State Tertiary Institutions
}

\author{
Adebisi O. Olorunfemi \\ Department of Educational Management, Lagos State University, \\ Tel: 234-80-8098-4578 E-mail: bisiyinka@gmail.com
}

Received: March 19, 2013 Accepted: May 31, 2013 Published: May 31, 2013

doi:10.5296/jse.v3i2.3410ＵRL: http://dx.doi.org/10.5296/jse.v3i2.3410

\begin{abstract}
A metropolitan city like Lagos, suffers the harsh situation of terrible traffic caused by overpopulation and bad roads. To get to work punctually and return back home on time is like a mirage to several workers. This definitely will affect performance and productivity of workers. Telecommuting has been found to be the solution to similar challenges in some other nations of the world. How far this Quality-of-Worklife (QWL) programme has been implemented in Nigeria in general and Lagos State in particular, is the focus of this study. A survey was carried out on a randomly sampled 1000(715returned) women working in four government owned tertiary institutions in Lagos State of Nigeria, looking at a number of factors that could affect the QWL of workers. Interview was also administered on the executive officers of the institutions. Interval scale was used in scoring the Likert response options given for items on the questionnaire. It was found that women workers on a general note had a high level of organizational pressure factor influence on quality of work life. The recommended solution was for the management of institutions to come up with policies that promotes telecommuting as a means of reducing organizational pressure, increase productivity and increase the quality of work life.
\end{abstract}

Keywords: Telecommuting, Quality-of-worklife, Women workers, Productivity, Lagos state 


\section{Introduction}

One of the major organisational factors impinging on quality-of-worklife (QWL) is the work-scheduling. The traditional eight hours per day work hours, has been found not to contribute to high performance on the part of some workers. Some workers, either on health grounds or domestic demands, cannot put in the required eight (8) hours, or not at the scheduled period of the day the organization has fixed. Such workers would engage in more absenteeism, sick leave than normal, thus affecting the productivity of the organisation negatively.

Many companies have found out that coming up with programmes to help employees balance work with outside needs, pressures and interest, can make them realize benefits in increased productivity and reduced turnover (Business for Social Responsibility, 2005). The concept of QWL is precipitated on this need to ensure total fulfilment by the workers while on the job and maximization of productivity on the part of the organization. The various programmes initiated by organisations to meet these needs has among it, very importantly, flexible timing and telecommuting.

Telecommuting and Telework were coined by Jack Nilles in 1973. The former refers more specifically to work undertaken at a location that reduces commuting time - inside the home or at some other remote workplace - which is facilitated through a broadband connection and computer or phone lines and possibly, also including the use of a writing instrument, paper, and the postal system. The latter on the other hand refers to, all types of technology-assisted work conducted outside of a centrally located work space, which includes works undertaken in the home (Wikipedia, 2013). The United States government defines telecommuting as 'the ability to do your work at a location other than your 'official duty station', on a routine, regular and recurring basis' one or more days in a week (Woog, 2013).

Tertiary institutions are citadels of learning where novel ideas emanate from, and the base for best practices. The introduction of telecommuting into worklife, should be well embraced and practiced by a $21^{\text {st }}$ century tertiary institution. Considering that the population of candidates seeking admission yearly is ever on the rise, virtual learning is becoming an acceptable option for the young secondary school leavers. Virtual learning would apparently require virtual teaching too, hence the relevance of telecommuting and telework in tertiary institutions.

It is estimated that over 50million U.S. workers ( $40 \%$ of the working population) could work from home at least part of the time. Sometime in 2010, the Federal Government of America passed the Telework Enhancement Act of 2010 so as to improve continuity of operations and ensure essential Federal functions are maintained during emergency situations, to promote management efficiency when telework is used, to achieve reductions in organisational and transit costs and environmental impacts and to enhance the worklife balance of workers. For example, telework allows employees to better manage their work and family obligations and this helps retain a more resilient Federal workforce that is better able to meet agency goals. 
In view of the above, it is pertinent to look at the extent to which the use of telecommuting has gone in tertiary institutions in Lagos State of Nigeria. The questions that formed the basis for this research includes:

i) What is the effect of telecommuting on staff turnover?

ii) Is the use of telecommuting viable in Lagos State tertiary institutions?

iii) What efforts are geared in the direction of promoting telecommuting?

It is believed that the outcome of this study will; steer up further investigation into the areas that were not covered by it, ginger the management of the various tertiary institutions into putting telecommuting on their priority list, and propel a national debate which will hopefully emanate into a legislature in favour of making telecommuting a regular part of worklife in Nigeria.

\section{Review of Literature}

The case study of an information technology professional revealed that he was available at work 24hours and 7days a week, yet he was most of the time on phone communicating with his professional colleagues scattered all over the world. This, it was discovered, he could do from home without jeopardising the organisational goals; hence the need for telecommuting (Reynolds, 2012). The case in favour of telecommuting is very strong and according to UC Berkeley (2013), it can be classified into five broad categories, that is, technological factors, economic factors, human and societal factors, industrial organisational factors and regulatory factors.

Technological Advancement has made it more attractive for workers to opt for working from home. The availability of residential internet access, the interconnectivity between home and office through intranets and the possibility of video/ audio conferencing, all make it easier for one to work from home and not miss out of important corporate contacts or meetings. The fact that organisations will be saving so much in terms of office space also makes it a readily acceptable option. Rathee (2013) considered telecommuting a benefit in that, overheads would be saved up to about $30 \%$. This is made possible when a number of employees are allowed to telecommute a few days a week, while they can all share office space and furniture. In fact, IBM consolidated 400,000square feet of office space into 100,000 square-foot facility at Crawford, New Jersey as a result of telecommuting. Meanwhile, AT\&T made a substantial savings in real estate cost when it was able to close an entire office complex, by allowing telecommuting, thus saving \$6,333,124 annually (UC Berkeley, 2013).

Further on, organizations are beginning to appreciate the increase in productivity brought about by telecommuting. The increase has been valued at about 20\%. Again for AT\&T, annual gain due to increase in productivity was valued at \$5,112,841. In Crosby (2013), a survey of 2007 by Kenexa Corp., a recruiting firm, as reported by the Wall Street Journal, revealed that $70 \%$ of workers took pride in working from home and $73 \%$ of telecommuters were satisfied with their company, as against $64 \%$ of commuters. This was probably as a result of the feeling by employees that they are trusted by their employers well enough not to give them close 
monitoring. This argument was further strengthened by the American Telecommuting Association which reported employee productivity rising from $10 \%$ to $15 \%$.

Telecommuting could also increase productivity when there is reduced distractions caused by overbearing boss or colleagues who would want some time out chatting. The time spent commuting has been found to be a great asset when converted to use at home or at a telework center. This is because the mental and physical activity level of the worker could have been reduced by the stress of commuting, especially if he has to battle through a heavy traffic. Furthermore, the fact that there is flexibility on the part of the worker to schedule his work around his most effective periods and around the other demands of his life extracts the best in terms of productivity from him. Rathee (2013) in agreement says that when you allow your employees to work from their homes, they will be able to work at the times they are feeling the most productive. Moreover, they will be able to better balance their home and worklife, allowing them to take time out for appointments or other obligations without missing out on work. In addition, workers would most likely stay back at home when they are slightly ill, thus reducing the aggregate productivity of the company. However, such workers could still work at home if allowed to telecommute and as such not affect the overall productivity level of the company. Cox (2009), agreed to the fact that telecommuting improves economic productivity. Research demonstrates that economic productivity is enhanced by minimizing travel to work and by increasing the number of jobs that can be accessed by people.

In tangential to the increase in productivity is the reduction in attrition rate of employees, as a result of telecommuting. In a study carried out by Bloom, Liong, Roberts and Ying (2013) on 16,000 call center employees of CTrip, a top rated Chinese travel agency, it was found after 9months of experimenting telecommuting, tagged (Work From Home 'WFH') on some volunteer workers and commuting on others, that, WFH workers reported improved work satisfaction and experienced less turnover. The home working led to $13 \%$ performance increase and this led to the CTrip company to roll out the options for workers to either work from home or commute. Over $50 \%$ of the workers that telecommute during the experiment opted to WFH, which invariably increased performance further to $22 \%$. In the analysis of Global Workplace Analytics and Telework Research Network, it was reported that, two third of employees would take another job to ease the problem of commuting. Moreover, it was said that, the cost of replacing an employee extends beyond the recruiting process. It includes separation costs, temporary costs, and lost productivity, training costs and frequently lost customers, coworkers and corporate intelligence.

Among the five reasons why employers should implement corporate telecommuting programmes for their staff, as outlined by Pinola ( 2013), is that , increase employee retention do help to attract new staff and telecommuting has been found to be an excellent incentive when looking for additional skilled staff in occupations that are high in demand. It was affirmed that, 'happier employees are usually better employees, and telecommuting, definitely increases employee job satisfaction and, thus, loyalty'. It was further asserted that, telecommuting is becoming a viable work alternative for many people and can attract more individuals into the work force and retain them there ( Encyclopedia of Business and Finance, 2013). 
Very importantly are the benefits of telecommuting to the government. It has been found to assist in achieving public policy goals such as, containing the growth of traffic congestion and reducing environmental pollution through the emissions of gas into the air by the large number of vehicles involved in daily commuting. Telecommuting according to Cox (2009) has the potential to eliminate 136billion miles of vehicle travel and 55million metric tons of carbon dioxide emission per year by 2020. Hence, the US Federal government's adoption of telework outpaces private sectors adoption by a 3-1 margin. In 2007, 44\% of Federal employees survey said they had the option to telework compared to $15 \%$ of those in the private sector and $62 \%$ of federal agencies now have written policies covering telework (Woog, 2013). The policy on employing the physically challenged persons is made more achievable when someone who ordinarily might find it extremely stressful to commute to work or would need the support of some other people to get to work, could now do his work from home without the stress associated with commuting. On the whole, the employment rate can improve as against increase in unemployment that would come up when workers have to relocate their accommodation far away from the organization (Boyd, 1996).

\section{Reports on Best Practices in Telecommuting}

The progress reported so far at the Duke University by Keohane and Roth (2003) includes some significant policies adopted by the Academic Council of the University. One of such was, to erase the challenge of competing work-life demands by giving formal guidelines that allow for flexible work arrangements which was developed by the Human Resources of the University. These guidelines take into account best practices, and include arrangements, as appropriate, such as flextime, telecommuting, compressed work schedules, abbreviated schedule, part-time work and job sharing.

The American Business Collaboration for Quality Dependent Care (2006) reviewed a number of studies carried out on issues relating to job-satisfaction and quality- of- work life by the American Business Collaboration (ABC). The $\mathrm{ABC}$ is a consortium of seven major corporations, that is, IBM, Johnson \& Johnson, Deloitte, Abbott, Texas Instrument, Exxon Mobil and Princewaterhouse Coppers. It came up with the results of its 'New Career Paradigm' study, revealing that the factors that make people satisfied with their jobs change from decade to decade. It reported studies carried out by some other organizations. These include the Watson Wyatt study which showed that flexibility in work arrangements can drive a $3.5 \%$ increase in shareholder value.

Also, the WED consulting, a firm that helps companies improve their work environments and enhance employee commitment, found that some 83\% of USA's Corporate employees work in different locations from their co-workers and those who work from home are significantly more likely to be committed to the company, productive and successful at worklife integration than their on-site colleagues.

Among the successful work/life initiatives that University of California and other employers have taken, is the awareness that employees are real people with real lives - as well as human resources - are; telecommuting, tailored job structuring, flexible project teaming, job sharing, alternate work schedules, compressed work weeks, employee assistance and referral 
programmes, disability return-to-work programmes, childcare services, eldercare resources and catastrophic leave sharing.

Ford Motor Company, as reported by Business for Social Responsibility (2005), stated its policy on improvement of work-life as thus;

We recognize you do your best work when you can balance your challenge and rewarding working-life with other interests and commitments to your community, to your loved ones, and to yourself. For Ford Motor Company, helping you find that balance is a corporate commitment. Our worklife Initiative has developed programs for transitional work arrangements, flextime, telecommuting, childcare, parenting, eldercare, wellness and fitness. These program help you maximize both your own personal growth and your contribution to the company, through these programs, we aim to attract and retain top professional talent, generate goodwill inside and outside the company, make our people as productive as possible, and make worklife initiatives a valued part of our corporate culture

It is apparent that telecommuting is a laudable programme, having recorded such level of success at the various organisations earlier mentioned. However, it has not received global recognition and awareness as expected, thus, developing nations like Nigeria still has a lot to garner from the experiences of the successful cases recorded so far.

\section{Methodology}

A survey was carried out on a population of women working in four government owned tertiary institutions in Lagos State, Nigeria, while some executive officers of the institutions were also interviewed.

The response from the administered questionnaire was from 715 randomly sampled women. The questionnaire got validated using Cronbach Coefficient Alpha and a high reliability coefficient $(\mathrm{r}=.815)$ was ascertained through Pearsons Product Moment Correlation Coefficient after a test-retest. The internal consistency was affirmed through item analysis at significance level of 0.05 .

The fixed alternative items were scored by the use of nominal scale and were analyzed by the use of simple percentages, line-chart and table.

\section{Findings and Discussion}

The research questions were addressed using the relevant data acquired from the survey and interview carried out. Herein were the findings, following on each research question.

\section{What is the effect of telecommuting on staff turnover?}

It is now rare for a person to stay with a single company his or her entire working life. Because employees are often willing to leave a company for better opportunities, companies need to find ways not only to hire qualified people, but also to retain them. Hence, to attract and retain employees, institutions need to continuously work with employees to redesign the work, eliminate stress, increase job autonomy, provide learning and training opportunities, and improve the quality of work life (enotes, 2013). One of the fast growing strategies adopted to 
retain workers is telecommuting (Pinola, 2013; Encyclopedia of business and finance, 2013; Bloom et al, 2013; Work life and human capital solutions, 2013). Overwhelmingly, the argument in favour of adopting telecommuting as a means of retaining workers cannot be overemphasized.

In Lagos State tertiary institutions, the staff retention ability seems to be quite low. Table 1 revealed that all the four institutions had their largest number of respondents falling within the range 1-10 years (53.3\%) of working experience and this is followed by $11-20 y e a r s ~(29.7 \%)$. One could then infer that most institutions would have majority of their workforce having worked for just ten years and below. There are a number of issues that could be responsible for the declining trend in workforce as years increase. A major factor could be due to staff turn-over, a situation where workers move from one institution to another in search of better QWL. The absence of alternative work options such as telecommuting could be responsible for this trend in the Lagos State tertiary institutions. When roads are in deplorable states and causing heavy traffic, as the case is on a good number of roads in Lagos State, it tends to increase the cost of commuting. On a general note, public or civil servants in Nigeria are poorly paid, with disposable income below average. Transportation expenses usually take a big chunk of the grossly insufficient income, thus reducing the standard of living the more. The quick option for the workers in this situation is to seek for a better paying job or a job in a place where not so much will be expended on transportation. This possibly explained the high percentage of workers within the low number of years in service. Those who have stayed long on the job might have some other considerations that are keeping them there, but they might also be living with a very low quality of work life. Telecommuting has been found to be a solution to this kind of situation.

Table 1. Table Showing How Long Respondents Have Been on the Job

\begin{tabular}{|c|c|c|c|c|c|c|}
\hline & & & \multicolumn{3}{|c|}{$\begin{array}{c}\text { For how long have you been on } \\
\text { this institution? }\end{array}$} & \multirow[t]{2}{*}{ Total } \\
\hline & & & $1-10$ & $11-20$ & $21+$ & \\
\hline \multirow[t]{8}{*}{ INSTITUTION } & UNILAG & Count & 103 & 35 & 30 & 168 \\
\hline & & \% within INSTITUTION & 61.3 & 20.8 & 17.9 & 100 \\
\hline & LASUTH & Count & 94 & 33 & 24 & 151 \\
\hline & & \% within INSTITUTION & 62.3 & 21.9 & 15.9 & 100 \\
\hline & LUTH & Count & 118 & 89 & 26 & 233 \\
\hline & & \% within INSTITUTION & 50.6 & 38.2 & 11.2 & 100 \\
\hline & LASU & Count & 66 & 55 & 42 & 163 \\
\hline & & \% within INSTITUTION & 40.5 & 33.7 & 25.8 & 100 \\
\hline \multirow[t]{2}{*}{ Total } & & Count & 381 & 212 & 122 & 715 \\
\hline & & \% within INSTITUTION & 53.3 & 29.7 & 17.1 & 100 \\
\hline
\end{tabular}




\section{Macrothink}

\section{Is the use of telecommuting viable in Lagos State tertiary institutions?}

The viability of telecommuting in Lagos State tertiary institutions is hinged on the availability of the necessary supporting infrastructures such as; uninterrupted power supply, the information communication technology devices, telework location and sufficient broadband for wider area network to connect home to the office. The issue of uninterrupted power supply cannot be compromised for telecommuting to be effective. Once there is power outage, everything gets grounded except if there is an alternative source of power like, generator and inverter. Of course, such alternatives pose extra financial burden on the worker who might not want to bear such costs. Moreover, the cost of acquiring a computer set and getting connected to the internet is only within the reach of the above average workers alone. Maintaining the internet connection is another big financial burden for even the above average workers; talk less of the general work force. Even the service providers of internet connectivity have not been able to meet up to expected standard of uninterrupted internet connection.

From the study, it was found, as express in figure 1 that women workers had not been performing to expectation for a number of reasons ranging from items Q1 to Q16. Items Q10 to Q16 expressed the high level of pressure emanating from the job which negatively affects the home relationship. These items happen to be issues that the introduction of telecommuting could perfectly address. From the responses to the questionnaire, about $62 \%$ of the respondents showed their dissatisfaction to access to internet sponsored by the organization. It is obvious that this QWL facility has not been made available to the majority of women workers. The viability of telecommuting in Nigeria, and particularly Lagos State is at very low ebb for now, until some very definite actions are taken to improve on the supporting facilities that would enhance its smooth running.

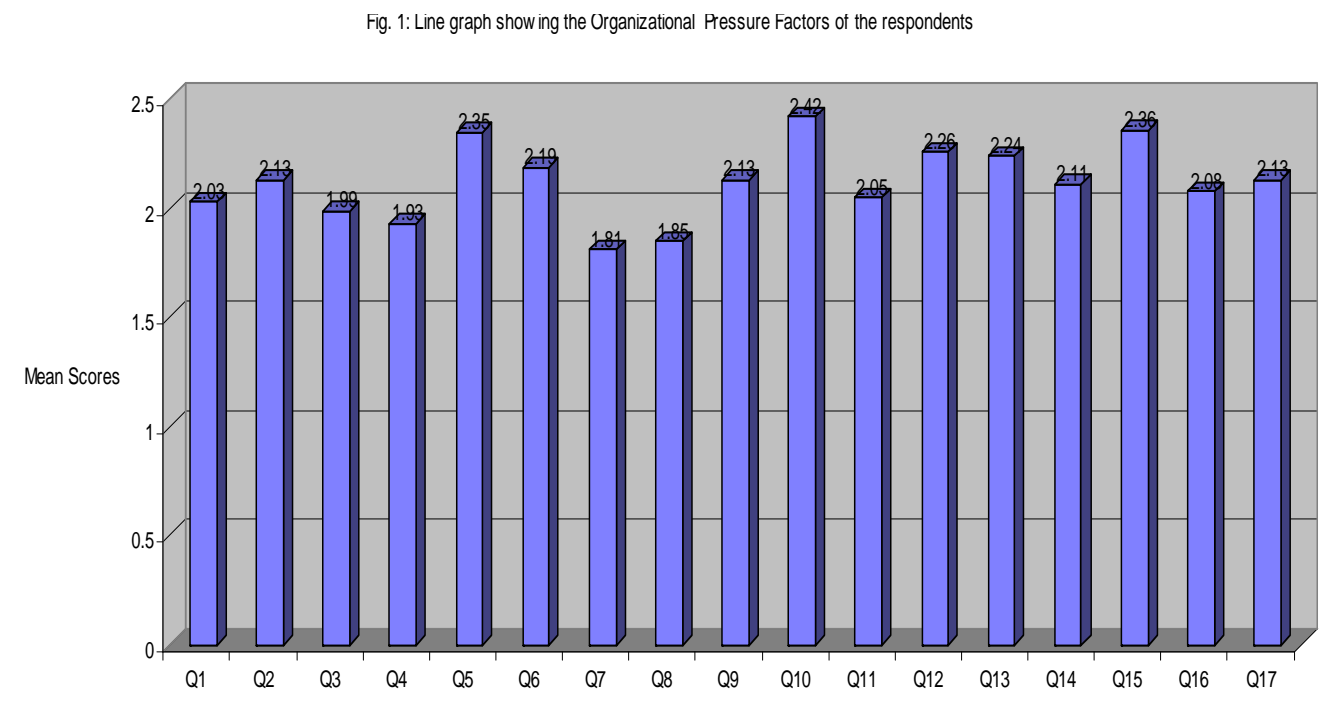

Figure 1. Line graph showing the responses to organisational pressure factors affecting performance 
Key to Organisational Pressure Factors

Q1 -unfairness to female workers in the area of promotion.

Q2 -male workers considered first for attainment of positions

Q3 -No twelve (12) weeks of maternity leave

Q4 -promotion and status are lost during maternity leave

Q5 -No day-care centre within institution’s premises

Q6 -Permission to attend professional conferences and workshops rarely gets to women workers.

Q7 -force involvement in religious activities by one's superior

Q8 -workload being negatively affected by personal religious activities

Q9 -Private business to supplement income affects organizational workload.

Q10 -No flexible-working hours for women workers on self-sponsored part-time training programmed.

Q11 -workload leading to unpleasant behavior at work and at home.

Q12 -Tiredness and job-stress deprives time with children

Q13 -Late coming from work becomes unbearable to husband

Q14 -Difficulty in coping with workplace and home responsibilities.

Q15 -workload pressure inhibits career development.

Q16 -Home suffers for attempt to satisfy work.

\section{What efforts are geared in the direction of promoting telecommuting?}

Going by the responses given during the interview of the management level officers of the institutions, it is obvious that quite a number of them expressed the desire to include flexible working hours as part of the measures towards improving quality-of-work life of women workers. Telecommuting was also identified as one of the techniques by which women workers can be relieved of stress, both at home and at work. However, the gap between the desire to put these programmes in place and the actual execution is still very wide. Matanmi (2007) has clearly stated that the working environment remains a central variable in the reckoning and evaluation of performance. He noted that organisations in the modern sector of Nigeria have contributed to explore benefits that are derivable from the advances in modern organisational and production technology for the enhancement of corporate performance and the fulfillment of the inclusive goals of the organisation. But if the pursuit of organisational goals are not harmonized with the demands of the work environment, such goals are hardly achievable. He noted that, an organisation's management must squarely address the often impelling emergent problems of the working environment, including the conditions of 
employment such as, work scheduling, working hours, noise pollution, prolonged darkness due to power failure, monotony and so forth. It is for this reason that the managements of work organisations in Nigeria, should consciously employ rational environment, if the numerous goals of corporate organisations are to be wholly attainable. Matanmi further noted that, one of the contemporary challenges of an organisation's management is how to maximize the value-added productivity derivable from the advances in organisational production technology, but particularly also minimize the inherent adverse impact on the quality-of-worklife, and the changing needs and aspirations of employees in the increasing complex world of work. Thus, beyond sheer competitive wages, the optimization of the work environment is an antidote for organisational productivity decline.

Visibly, there is no effort on the part of the management of the tertiary institutions in Lagos State to make telecommuting an option for the workers, even though it is desired. It is perceived that the reluctance to make this option available could be either because of the financial implications, which presently, is a limiting factor for most tertiary institutions in Nigeria, or because the management could fear the possible abuse of it by the workers. Nonetheless, it is apparent that, for the African race to develop as expected, there has to be some proactive decisions by the leaders to improve national productivity by making work available to all those who can, and are qualified to work, by removing every possible barriers which commuting could create.

\section{Conclusion}

Telecommuting in recent times have been found to be an effective way of combating poor quality -of -worklife of workers, especially working women who have to combine career and homemaking. The programme has been found to be profitable to both the employers and the employees and as such it is fast gaining wide acceptability and recognition. In view of the fact that this is a problem solving strategy, the case of Lagos State tertiary institutions was looked into in this study. A survey carried out in four degree awarding institutions and focusing on women workers, revealed that the larger percentage of the workers do not stay long enough in the organisation which could be as a result of poor condition of service, insufficient income and high expenditure on transportation. Other social factors that could be responsible, include, inability to cope with work and home challenges, and relocation of personal house accommodation to a farther distance away from the job site location.

The introduction of telecommuting into the Nigerian work system has been considered not viable now due to the non-availability of the necessary infrastructures required to make it work. Poor and erratic power supply is a major inhibiting factor. The high cost of purchasing and maintenance of the required information technology is another deterrent to the smooth operation of telecommuting in Lagos State tertiary institutions.

It is therefore recommended that human resources experts should give more awareness to the government and executive managers of institutions on the importance of the introduction of telecommuting into their work programmes. Some notable institutions, such as, Columbia University, University of California, Duke University and so forth, have official telecommuting guidelines for workers requesting for a telecommuting arrangement. This 
could act as a point of reference to the Lagos State tertiary institutions for steps to be taken in similar direction. Moreover, it is pertinent that Laws promoting telecommuting be enacted to guide employers of labour in tertiary institutions. First, telecommuting should always be an available option for the workers and secondly, ICT devices required and supportive infrastructures should be put in place to make the programme viable.

\section{References}

Anonymous. (1998). '1998 UC Worklife Symposium’ University Of California Publication. http:///www.ucop.edu/worklife/news/news.html

Anonymous. (2005). "Work-Life Quality" in Business for Social Responsibility http:www.bsr.org/CSR Resources? Issue Brief Detail. Cfm? DocumentID-50965

Anonymous. (2006). American Business Collaboration For Quality Dependent Care. http://www.abcdependentcare.com/docs/current-news.shtml

Anonymous.

www.enotes.com/telecommuting-reference/telecommuting-174517

Telecommuting. 2013

Anonymous. (2013). The business case for telecommuting , In Work life and Human Capital Solutions

worklifeexpo.com/EXPO/docs/The_Business_Case_For_Telecommuting-WFCResources.pdf retrieved March 9.

Bloom, N., Liong, J., Roberts, J., \& Ying, Z. J. (2013). Does working from home work? evidence from a Chinese experiment. www. Stanford.edu/ᄀnbloom/WFH.pdf retrieved March 7, 2013

Boyd, P.C. (1996). Six organisational benefits of telecommuting. research-advisors.com/article/ttorgbens.html, retrieved January 29, 2013

Cheuk, F. N. (2006). Academics telecommuting in open and distance education universities: issues, challenges, and opportunities. www.irrodl.org/index.php/irrodl/article/view/300/632 retrieved December 6, 2012

Cox, W. (2009). Executive summary: improving quality of life through telecommuting in the information technology and innovation foundation. www.itif.org/files/Telecommuting.pdf retrieved January 25, 2013

Crosby, T. (2013). How telecommuting works. home.howstuffworks.com/telecommuting2.htm. retrieved January 29, 2013

Keohane, N.O. and Roth, S. (2003). Report of the steering committee for the women's initiative at Duke University, in Women's Initiative http://www.duke.edu/womens-initiative/report-report.htm

Kerlinger, F.N. (1992). Foundations of behavioural research, $3^{\text {rd }}$ ed. Orlando: Harcourt Brace College Publishers. 


\section{Macrothink}

Journal of Studies in Education

ISSN 2162-6952 2013, Vol. 3, No. 2

Lotich, P. (2013). What are the benefits and disadvantages of telecommuting? thethrivingsmallbusiness.com/benefits-and-disadvantages-of-telecommuting/ retrieved February 2, 2013

Matanmi, O.O. (2007). Employment relations that endure: lesson for Nigeria. 31st Inaugural Lecture, Lagos State University

Pinola, M. (2013). 5 Reasons employers should implement corporate telecommuting programs. Mobileoffice.about.com/od/getmobilized/tp/employer-benefits-of-telework.htm retrieved March 7, 2013

Rathee, A. (2013). The benefits of telecommuting for organizations. info.infinteconferencing.com/bid/90696/The-Benefit-of-Telecommuting-for-Organisations retrieved February 1.

Reynolds, B. W. (2012). Finding work-life balance through telecommuting: confessions of a virtual employee - how I quit working as hard. www.flexjobs.com/blog/post/finding-work-life-balance-through-telecommuting/, retrieved February 1.

UC Berkeley. (2013). Flexible work arrangements: benefits of telecommuting and flexible work arrangements. hrweb.berkeley.edu/er/leaves/flexible/benefits retrieved February 1.

University of California. (2008). UCLA staff employee telecommuting guidelines. map.ais.ucla.edu/go/1004111 retrieved March 7, 2013.

Woog, D. (2013). Telecommuting options in government jobs. govcentral.monster.com/benefits/articles/1732-telecommuting-options-in-governmentjobs retrieved February 1. 